\title{
Content Design of Aesthetic Systematics Course on Music Performance
}

\author{
Yumeng He, Weiyang Xu \\ School of Music, Liaoning Normal University \\ Dalian, 116029, China
}

\begin{abstract}
Aiming at the imperfections of music performance aesthetic course, this paper discusses the systematic characteristics of music performance aesthetic course, and analyzes the systematic relations of music aesthetic course from perspectives of relational beauty, hierarchical beauty and dynamic beauty, and puts forward the basic framework of establishing the aesthetic systematics course of the music performance major. The research shows that music aesthetic systematics extends the philosophical thinking of music aesthetics to systematic thinking, and represents the basic characteristics of music aesthetics in the new era. This research can provide effective guidance for the content and implementation mode of aesthetic education.
\end{abstract}

Keywords-music performance; music aesthetics; aesthetic systematics; curriculum construction

\section{INTRODUCTION}

At present, China has entered a new era of socialism, and music art field, like other fields, is facing strong traction of the demand of The Times. For the curriculum construction of music colleges and universities, how to construct music curriculum system of socialism with Chinese characteristics in the new era is an urgent problem to be solved in the construction of music specialized courses. On August 31, 2018 , the party committee of the ministry of education issued a notice on the study and implementation of the important reply spirit of general secretary $\mathrm{Xi}$ Jinping to the old professors of the central academy of fine arts, pointing out that "academic research on Chinese aesthetic education spirit should be strengthened. We should deeply study the rules of aesthetic education, discipline and evaluation." In order to deeply study the laws of aesthetic education, teaching, discipline and evaluation, the key problem is to have an aesthetic theory system that satisfies the characteristics of the new era of socialism with Chinese characteristics. From the perspective of music aesthetics and based on $\mathrm{Xi}$ Jinping thought of literature and art, this paper discusses how to design the course content of music aesthetic system science. The content of this paper is organized as follows: the first section introduces the research status at home and abroad. The second section analyzes the theoretical value and practical significance of music aesthetic systematics. The third section presents the design content of music aesthetic system and the research characteristics of music aesthetic system in the new era. The fourth section gives the conclusion of this paper.

This paper is the stage research results on "Music Performance Aesthetic Fuzziness and Cognitive Ability Evaluation Research", which is the funding project in the research of humanities and social sciences by education department of Liaoning Province.

\section{RESEARCH STATUS AT HOME AND ABROAD}

Music aesthetics is both an old topic and a new problem which is developing continuously. Music aesthetics has experienced from ancient to modern multiple stages of development, with the art of music aesthetics has jumped out of the traditional human civilization attributes, from the simple philosophy of music, music psychology and music sociology, music behavior subject attribute to return to the art of music aesthetic value, the reality of human aesthetic attribute, and gives the behavior of the music aesthetic function and social value.

Since the beginning of this century, the information age has presented severe challenges to music aesthetics research. Centering on the national characteristics of music aesthetics, psychological perception of music aesthetics, spiritual demand of music aesthetics, and moral standards of music aesthetics, researchers at home and abroad have conducted in-depth research on music aesthetics. From the research status abroad, different countries have different degrees of cognition on music aesthetics due to their differences in values and codes of conduct. Foreign music aesthetics researchers focus on music philosophy research of music works, while music aesthetic thinking focuses on music perception itself, from music to music, from art to art. The research focuses on the historical, national and spiritual needs of music works. The characteristics and development trend of music aesthetics research abroad can be used as an effective reference for rational analysis of music aesthetics in China

In the past 10 years, music aesthetic research in China has made rapid development, and has made gratifying achievements in the construction of music aesthetic discipline, the category of music aesthetic concept and proposition, music criticism and music aesthetics. According to incomplete statistics, more than 100 papers on music aesthetics have been published. Its research features and direction are centered on three aspects: one is the discipline nature: through the rational way studies the perceptual question; the second is the subject object: to care for pure forms (including sound forms and emotional forms) through the way of experience; Third, the subject method: describe and express music expression by means of written language.

From the research status of music aesthetics at home and abroad, it can be found that although some research literature mentioned the basic ideas and related concepts of system aesthetics, information aesthetics and control aesthetics, there 
has been no research on the system theory of music aesthetics. That is to say, music aesthetics needs to establish its systematic theory. Aesthetic education of socialism with Chinese characteristics in the new era is a systematic project, and this systematic project must be guided by solid theories. Music aesthetic system science is the theoretical basis of music aesthetic education, and music aesthetic education is an important part of aesthetic education. Therefore, the study of music aesthetic system science in the new era highlights its important significance.

\section{THE THEORETICAL VALUE OF MUSIC AESTHETIC SYSTEMATICS}

The research of music aesthetic system comes from the cognition of music aesthetics, and the systematic theory of music aesthetics and aesthetic education is the core of music theoretical system. Since different times, different nationalities and different social systems have their own characteristics and models for the construction of music theoretical system, it is inevitable to have music aesthetic research direction meeting the requirements of the new era in the historical stage of socialism with Chinese characteristics. Meanwhile, music aesthetics is an important content in the field of aesthetics. Therefore, how to construct music aesthetics system theory to meet the development needs of the new era is a difficult task for music theoretical researchers. Its theoretical value is reflected in the following aspects:

One from music esthetics Angle of systems thinking to the people as the center of music aesthetics as a whole is mapped to the dimensions of the aesthetic, the expansion of music aesthetic relationship with the people into music aesthetic education work and the elements of music system, making a lot of music research and practice have the characteristics of the new age of socialism with Chinese characteristics, from a certain Angle for the problem of the aesthetic values of music aesthetics.

Second, from the four aspects of music aesthetic system, elements, structure and function, to realize the paradigm transformation of music aesthetic theory from a single concept deduction to a real system logic, and realize the transformation of music aesthetic theory from the introduction of dependence to the systematic cognitive mode of subject confidence, which is a development of music philosophy. That is to say, the music aesthetic theory research is extruded from the long-term Mired in western theories and superstitions, and the music aesthetic theory with Chinese characteristics is established, which solves the problem of cognitive uncertainty of Chinese and foreign aesthetics to some extent.

Three is specified under the guidance of marxism, Chinese traditional, Chinese wisdom, China's contribution to the value of music aesthetic theory, from concept to the rule, from the path to the design, from the top to the measures for its implementation, a comprehensive, systematic to provide a new era of socialism with Chinese characteristics a new system of music aesthetics, music aesthetics in realizing the great rejuvenation of the Chinese nation on the contribution of the Chinese dream provides certain theoretical basis. The theory of music aesthetic system has great application value. Firstly, it provides new ideas and methods for music aesthetic theory research. For example, the systematic thinking of music creative aesthetics, the systematic method of music performance aesthetics, the systematic analysis of music works aesthetics, the systematic thought of music appreciation aesthetics, and the systematic method of music education have great application value. Secondly, music aesthetic system theory has great application value and development prospect in doing a good job in aesthetic education and carrying forward Chinese aesthetic education spirit.

\section{DESIGN OF Music AESTHETIC System COURSE}

\section{A. The basic framework of music aesthetic systematics}

\section{1) The basic concept}

Music aesthetics research involves all aspects of music discipline, and the correlation between different fields of the discipline has an impact on the formation of music aesthetics. Therefore, all the content related to music aesthetics is composed into a complex, which is called a music aesthetic system. Then, the system studying music aesthetic knowledge is called music aesthetic system. Music aesthetic elements determine music aesthetic system, so different music aesthetic elements constitute different music aesthetic system.

\section{2) The structure of music aesthetic system}

Centering on the study of music aesthetic system, all the issues to be discussed in music aesthetic theory can be incorporated into the aesthetic system. Music aesthetic system is composed of the essential beauty of music attribute and the formal beauty of music object. As shown in Fig.1:

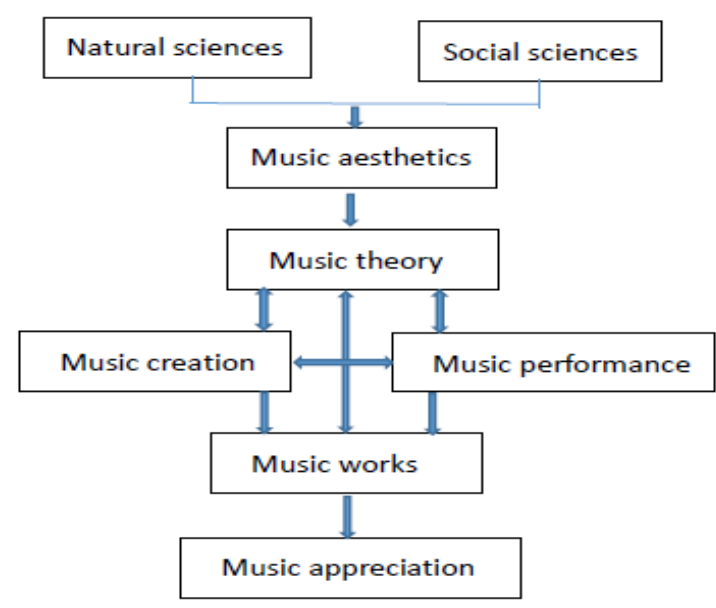

Fig. 1 The structure of music aesthetic system

\section{3) Characteristics of music aesthetic system}

General characteristics of music aesthetic system. Music aesthetic system has integrity, hierarchy, dynamics and fuzziness, which are the core content of studying music aesthetic cognition. According to the music aesthetics system structure, the music aesthetics system each element carries on the analysis. Specific contents include: 
(a) Music aesthetic relationship characteristics, specifically discuss the relationship between each music subsystem, the relationship between each subsystem music elements, each music subsystem and music elements on music aesthetic impact.

(b) The hierarchical characteristics of music aesthetics.

(c) Dynamic characteristics of music aesthetics.

(d) The integrity principle of music aesthetics.

The integrity of music aesthetics is the core of music aesthetic system theory research. Whether it is the essential beauty or the formal beauty of music aesthetic system, the system integrity principle plays an important role. The fuzziness and self-organizing function of music are the essential characteristics of music aesthetic system. Music aesthetics comes from the integration of music artistic essence and music object form uncertainty, which is the frontier problem of music aesthetic system -- music fuzzy aesthetic system. Music self-organizing function of aesthetic system. Self-organization optimization of music aesthetic system is the goal of music aesthetics systematization, and it is also the feature of music aesthetics research in the new era.

\section{B. The relationship characteristics of music aesthetic system}

\section{1) Music theory based on composition technology}

In the subsystem of music theory based on composing technology, each part does not exist in isolation, but is organically connected in music works. The changes of each part will directly affect the rest of the parts, and also directly affect the artistic quality of music works. The relationship between these subsystems is: "and acoustic" and "Stylistics", "and acoustics" and "polyphony", "And Acoustics" and "Orchestral Method", "and acoustics" and "melody", "Stylistics" and "polyphony", "Stylistics" and "orchestral method", "Stylistics" and "Melody science", "Polyphony" and "orchestral method", "Polyphony" and "melody science", "Orchestral method" and "Melody science".

\section{2) The aesthetic role of music creation subsystem}

This subsystem has a significant impact on other subsystems and the entire system. Music composition is closely related to the technical theory of composition. The development and changes of the technical theory of composition enable composers to use as diverse technical means as possible in their creation, while the creative labor of writers constantly enriches and develops the technical theory. Music works are the product of music creation.

All kinds of dynamic changes in music creation are reflected in music works. Therefore, music works are also in a very unstable dynamic. In the world, no identical music works can be found. This fact fully proves the dynamic nature of music works. We can judge the level of music theory according to the dynamics of music works. Judge the composer's creative thought, aesthetic taste, writing skills; Judge the talent, accomplishment and technical level of music performers, can also judge the music appreciation of the degree of culture, artistic interest. In a word, music works are related to each subsystem of music aesthetic system, which indicates the development trend of music art. It shows the music level of a country or region, a nation or an individual.

\section{3) The aesthetic role of music performance subsystem}

The relationship between music performance and the theory of composition technology is extremely close. Music performance fully expresses all kinds of details in the theory of composition technology; and the improvement of music performance ability will make the theory of composition technology explore and develop new performance fields. In addition, since the theory of composition technology is mastered by composers, the relationship between music performance and the theory of composition technology can be transformed into the relationship between music performance and music creation.

All of these relationships are dynamic. That is to say, music performance is a kind of creative labor of human beings, is another core of music practice activities. It can even have a broader and more direct impact than music authoring. It is an important subsystem that music aesthetics should always focus on. In the performance subsystem, the performance school, the work style and the performance technology are also in the dynamic, and the relationship between them is also closely linked. First of all, the comparative comprehensive study of the performance school guides the study of work style and performance technology. Different performance schools can make different artistic treatment of work style, and put forward different requirements for performance technology accordingly. Secondly, the style of works can also influence different schools of performance, and put forward different requirements for performance technology. Thirdly, the analysis and study of performance technology can rapidly improve the performance level, provide new possibilities for the perfect expression of the work style, and lay a solid foundation for the formation of a new performance school.

\section{4) The aesthetic role of music appreciation subsystem}

Music appreciation can be regarded as a series of psychological activities: auditory perception, emotional experience, imagination association, understanding and cognition. From the appreciation level, different levels of people, the psychological process is different. Low-level listeners can only achieve sound perception, intermediate listeners can achieve emotional experience and imagination association, and only high-level listeners can achieve comprehensive understanding. These three levels are progressive relations: the first level of the audience, can be familiar with music art and into the second level; the second level of the audience can gradually grasp music art and into the third level. This is just the way from the kingdom of necessity to the kingdom of freedom.

\section{DISCUSSION}

Using the basic method of music aesthetic system theory, the research framework and model of music aesthetics of socialism with Chinese characteristics in the new era are established. The research contents focus on :

(a) music aesthetics should be derived from life and truly reflect social life. 
(b) the core of music aesthetics is to set up people's aesthetics.

(c) music aesthetics should inherit the Chinese spirit as the ideological soul.

(d) music aesthetics should shape people's ideological character of truth, goodness and beauty.

(e) music aesthetics should reflect that nature and science are the wealth of mankind.

If the above five aspects are summarized, the research framework of music aesthetics in the new era can be formed.

In fact, music aesthetics in the new era is a systematic music aesthetics. This theoretical system of music aesthetics is full of systematic thoughts. In practical research, the music aesthetics of people, music aesthetics of Chinese wisdom, music aesthetics of Chinese spirit and music aesthetics of Chinese dream should be discussed from the perspective of system theory. All these reflect the integrity principle of music aesthetic system, which is full of music aesthetic big system thought. New age music aesthetic system theory to study the basic train of thought is: from the perspective of socialist core values, the music aesthetic standards defined by the beauty of music essence and form unifies, analysis and explore the aesthetic rule between music elements, types of music aesthetic system of function and role, and to build accord with the characteristics of the new age music esthetics theory system.

On this basis, how to establish a new era of Chinese characteristics of the socialist aesthetic education work research, give music aesthetic education system construction framework and operation mode, to achieve the great rejuvenation of the Chinese dream of music aesthetic theory system and implementation of the optimal design.

\section{CONCLUSIONS}

To apply systematics to music aesthetic activities, it is necessary to understand the structure, dynamics and mutual relations of music aesthetic system. At the same time, music aesthetics is a conceptual system that is constantly changing in space and time. Quantitative analysis method cannot be used for each subsystem of music aesthetics system. Only fuzzy thinking and fuzzy information processing can be used. Music creation, music works and music performances constitute the core of music practice. It is one of the important tasks of music aesthetics research to analyze and study the relationship between each subsystem.

\section{ACKNOWLEDGMENT}

This study was supported by the laboratory open project (CX201901031)of liaoning normal university, and also thanks to the funding project of liaoning education department. Here, we would like to express our thanks to the teachers and students who participated in these two projects. They are Kang Li, Sun Wei, Yu Nuofei, Yin Meixuan, Gao Bowen, Han Shiqi, Zhang Jiahui, Xu Ningze, Yang Wenting.

\section{REFERENCES}

[1] Lu Guang, System methodology and music aesthetics, Chinese musicology, 1985, pp.49-55. (In Chinese)

[2] The ministry of education issued "opinions on strengthening the aesthetic education of colleges and universities in the new era", http://www.sohu.com/a/308209261_99905178,2019-04-16/2019-8-23.

[3] Fu Rong, A brief analysis of the present situation and deficiency of contemporary music aesthetic education. http://theory.people.com.cn/GB/n1/2018/0112/c40531-29760968.html, 2018-01-12/2019-07-03.

[4] Sun Ke, The Theory and Practice of Musical Performance Aesthetics, Big stage, 2014, vol.4, pp.113-114. (In Chinese)

[5] Wang Yuxi, Research on music aesthetic value, Nanjing Art College, 2014, pp.16-32. (In Chinese)

[6] Chen Zhiyu, Chen Shiquan, A Cognitive Structure of Fuzziness Aesthetics, Fuzzy Systems and Mathematics, 2006, vol.20, pp.140-146. (In Chinese)

[7] Sheng Lulu, Aesthetic Features of Music Art, HUND RED SCHOOLS IN ARTS, 2013, vol.8, pp.298-299. (In Chinese)

[8] Chen Xinghao, The Realization of Piano Performance Aesthetic Value, Hunan Normal University, 2018. (In Chinese)

[9] Chen Guoping, Aesthetic principles and systematic approaches of Art classification study, Journal of Hubei Normal University (Philosophy and Social Science), 2005, vol.25, pp.23-28. (In Chinese) 